\title{
Originals
}

\section{Long-Standing Diabetes Mellitus in Ethiopia: A Survey of 105 Patients}

\author{
F. T. Lester \\ Department of Medicine, Yekatit 12 Hospital, Addis Ababa, Ethiopia
}

Summary. In 7 years, 809 Ethiopian patients have been seen in a diabetic clinic in Addis Ababa, of whom 105 have had diabetes for more than 15 years (none more than 30 years). Of those with "long term" diabetes 13 were Type 1 (insulin-dependent), 68 Type 2 (non-insulin-dependent) non-obese and 24 Type 2 obese; $28 \%$ had always taken insulin, and a further $19 \%$ required insulin after some years of oral therapy. Diabetic retinopathy was found in $38 \%, 27 \%$ had normal fundi, and $14 \%$ had cataracts so dense the fundi were obscured; for $21 \%$ fundal examination was not recorded. Cataracts were or had been present in $40 \%$ of patients, and caused more visual hand- icap than retinopathy. Thirty percent of patients had nephropathy. Diabetic peripheral neuropathy was found in 47\%. Cardiac, foot and miscellaneous vascular complications were seen, but were much less common. Thirty-one patients $(30 \%)$ died during the 7 years, the commonest cause of death being renal failure, but an encouraging proportion $(61 \%)$ had no severely handicapping complications and were independent after more than 15 years of diabetes.

Key words: Diabetes mellitus, complications, Ethiopia, retinopathy, neuropathy, nephropathy, diabetic mortality.
In 1980, a WHO Expert Committee commented that little is known of the incidence of diabetes or its sequelae in 'developing' countries [1]. It is the purpose of this paper to present information on the prevalence of complications in Ethiopians who have been diabetic for 15 years or more.

\section{Material and Methods}

Since March 1976, a twice-weekly diabetic clinic has been held at the Yekatit 12 Hospital, Addis Ababa, and has registered 809 Ethiopian diabetic patients in 7 years, $18 \%$ of whom came only once, $45 \% 2$ to 10 times, $23 \% 10$ to 19 times and $14 \%$ more than 20 times. Most were referred from the wards or general outpatient departments of this 300 bed general hospital, some were referred from other hospitals, and at least $17 \%$ came from outside Addis Ababa, some from as far as $350 \mathrm{~km}$, to obtain insulin.

Diabetes mellitus was diagnosed if the fasting blood glucose was $>7.2 \mathrm{mmol} / 1$, if random blood glucose was $>11.1 \mathrm{mmol} / 1$, or if the patient had a well-documented past history of treated diabetes. Obesity was diagnosed if men had body mass index of $>25 \mathrm{~kg} / \mathrm{m}^{2}$, and women $>27 \mathrm{~kg} / \mathrm{m}^{2}$.

In 7 years, 105 patients diabetic for 15 years or more have been seen. Duration was verified from old hospital records, repeated questioning of the patient at different visits, and relationship of onset to well-known historical events. All patients had complete physical examination. Blood glucose, weight, and blood pressure were determined at every visit, and urine analysis for glucose, protein, acetone and cells carried out frequently. Blood urea nitrogen estimation and chest radiograph were done at the initial visit if possible, and thereafter, as with other investigations, when clinically indicated.

Optic fundi were examined with the pupils dilated, and whenever feasible patients were referred to an ophthalmologist. Retinal photography and photocoagulation are not available in Ethiopia.

Diabetic nephropathy was diagnosed on clinical grounds in patients with persistent proteinuria, other identifiable renal disease being excluded by history, urine culture, plain abdominal radiograph and sometimes intravenous pyelography. Renal biopsy is not available, and autopsy is rarely obtained for religious and cultural reasons. Patients were considered hypertensive if the blood pressure was consistently $>160 / 95 \mathrm{mmHg}$.

The long-term complications of diabetes were classified as in the 1980 WHO Expert Committee Report [1].

Blood glucose is usually measured by the glucose oxidase method with Dextrostix and an Eyetone reflectance meter. Urine is examined for protein by precipitation with $20 \%$ sulphosalicylic acid.

Ethiopia, 'the roof of Africa', is a mountainous nation of about 30 million people, a mixture of Hamitic, Semitic and Nilotic origins, with only about 600 physicians and 70 hospitals in the whole country [2]. Life expectancy is 45 years for men and 41 for women, and the problems of infectious diseases and malnutrition dominate the health scene [2]. The prevalence of diabetes mellitus is unknown but it accounts for $2-3 \%$ of admissions to adult medical wards. There are only two diabetic clinics in the country, both in Addis Ababa. Supplies of insulin and oral hypoglycaemic agents are often undependable, especially in the rural areas, and the cost of drugs prohibitive in a nation where most people earn less than 100 American dollars per month; free treatment is available only to those earning less then \$ 25 monthly, and insulin costs around $\$ 3.50$ per vial. Most patients must eat the least expensive food, when it is available, and farmers and labourers 
Table 1. Causes of death in Ethiopian patients who have been diabetic for $15-30$ years

\begin{tabular}{lc}
\hline Cause & $\begin{array}{l}\text { Number of } \\
\text { patients }\end{array}$ \\
\hline Chronic renal failure & \\
Due to nephropathy & 11 \\
Due to stricture and pyelonephritis & 1 \\
Cardiovascular & 3 \\
Myocardial infarct & 1 \\
Complete heart block & 4 \\
Cerebrovascular accident & 2 \\
Ischaemic gangrene and sepsis & \\
Miscellaneous & 2 \\
Cor pulmonale after tuberculosis & 1 \\
Pneumonia after hypoglycaemic coma & 1 \\
Alcoholic liver cirrhosis & 1 \\
Hepatoma & 1 \\
Carcinoma of pancreas & 1 \\
Insulin suicide & 1 \\
Pulmonary tuberculosis & 1 \\
Ketoacidosis after eclampsia and abortion & 31 \\
\hline
\end{tabular}

customarily eat only once daily. For such social and economic reasons, ideal control of diabetes is rarely obtained. Most insulin-dependent patients, on once- or twice-daily regimens, can check urine for glucose and adjust their dose, but Clinitest is expensive. The type of insulin often has to be changed because a type previously in use disappears from the country, thus making therapy inconsistent. Insulindependent patients are usually seen every $2-3$ months, the others less often.

\section{Results}

\section{General Features}

There were 57 men and 48 women who had been diabetic 15 years or longer. Eight had had onset before the age of 15 years. There were 13 Type 1 diabetics, 68 Type 2 non-obese and 24 Type 2 obese. Eight patients had body mass index of $<18 \mathrm{~kg} / \mathrm{m}^{2}$; only four had a body mass index $>30 \mathrm{~kg} / \mathrm{m}^{2}$. Only three had ever regularly smoked cigarettes, a habit uncommon amongst Ethiopians until the present generation.

Diabetes mellitus had been present 15-19 years in 68 patients, $20-24$ years in $29,25-29$ years in seven and 30 years in one. Mean age of patients at latest visit or death was 53.7 years; 34 of the 105 patients were $>$ 60 years old.

All Type 1 and 16 of the Type 2 patients had always been treated with insulin, and 20 further patients needed insulin after several years of oral hypoglycaemic therapy. The others had been treated with tablets. Attempts at therapy with diet alone generally fail either because the patient cannot comply, or he does not return for follow up if medicine has not been prescribed.

\section{The Eyes}

Twenty-one patients were lost to follow up or died without adequate examination of the fundi having been recorded. Of the remaining 84 patients, the fundi were obscured by dense cataracts in 14 and by smallpox scars in one. Forty patients had diabetic retinopathy, complicated by retinitis proliferans in eight. Twenty-eight patients had normal fundi. Thus, $38 \%$ had diabetic retinopathy, $27 \%$ had normal fundi, and the state of the retina is unknown for $35 \%$.

A total of 42 patients $(40 \%)$ had cataracts or had had cataract surgery, in 14 of whom the cataracts were so dense that the fundi could not be seen. Three of these 42 had had so-called 'metabolic cataracts' extracted early in the course of poorly controlled childhood diabetes. There was more blindness and severe visual handicap from cataracts than from retinopathy.

When cataracts and retinopathy are considered together, four of these 105 long-term diabetic patients were blind when last seen, and a further 13 were severely handicapped by visual impairment.

\section{The Kidneys}

Sixty-nine patients had no proteinuria and no evidence of renal disease. Two had recurrent urinary tract infections, one had urethral stricture and renal failure, and one had nephrolithiasis.

Thirty-two patients $(30 \%)$ had persistent proteinuria, associated with hypertension in all but one. Twenty of the 32 had diabetic retinopathy and seven had cataracts, one had normal retinae and fundal examination was not recorded for four subjects.

Fifteen of the 32 patients with diabetic nephropathy had chronic renal failure, 11 of whom died during the 7 year period. The exact time of onset of asymptomatic proteinuria is not known for most, as they have attended different hospitals over the years. All who died in renal failure had diabetic retinopathy. (Chronic haemodialysis and renal transplantation are not available in Ethiopia.)

The incidence of nephropathy rises with duration of diabetes in patients seen in this clinic, from $1.9 \%$ at $1-5$ years to $35.3 \%$ at $21-25$ years [3].

\section{Neuropathy and the Feet}

Fifty-one patients (49\%) had no clinical evidence of diabetic neuropathy. Information was incomplete for five. Peripheral neuropathy, with loss of sensation in the legs and feet and absent reflexes, was found in 49 of the 105 patients $(47 \%)$. Three of these also had mononeuropathies, two had gustatory sweating and two unexplained nocturnal diarrhoea.

Six patients have had repeated infections of the feet, one complicated by osteomyelitis and one requiring amputation. Two other patients required amputation 
Table 2. Diabetic complications in African countries

\begin{tabular}{|c|c|c|c|c|c|c|c|c|}
\hline \multirow[t]{2}{*}{ Centre } & \multirow[t]{2}{*}{ Reference } & \multirow{2}{*}{$\begin{array}{l}\text { Total } \\
\text { number of } \\
\text { diabetic } \\
\text { patients } \\
\text { studied }\end{array}$} & \multicolumn{2}{|c|}{$\begin{array}{l}\text { Long-term diabetic } \\
\text { subjects }\end{array}$} & \multicolumn{4}{|c|}{ Complications (\%) } \\
\hline & & & $\begin{array}{l}\text { Duration } \\
\text { (years) }\end{array}$ & $\begin{array}{l}\text { Number of } \\
\text { patients }\end{array}$ & Retinopathy & Cataracts & Neuropathy & Nephropathy \\
\hline Kampala, Uganda & 4 & 105 & $16-25$ & 6 & 33 & - & - & - \\
\hline $\begin{array}{l}\text { Nairobi, Kenya } \\
\text { Dar es Salaam, }\end{array}$ & 5 & 100 & $\begin{array}{l}10 \\
\text { average }\end{array}$ & 20 & - & - & & 80 \\
\hline Tanzania & 6 & 139 & 4.9 & $?$ & 25 & 12 & 32 & 14 \\
\hline Ibadan, Nigeria & 7 & $?$ & $>10$ & 52 & 14 & 6 & 70 & 26 \\
\hline Dakar, Senegal & 8 & 652 & & $?$ & $? 44$ & 11 & 6 & 13 \\
\hline Addis Ababa & 9 & 404 & $>15$ & 21 & 50 & - & 38 & 44 \\
\hline Addis Ababa & Present study & 809 & $15-30$ & 105 & 38 & 40 & 47 & 30 \\
\hline
\end{tabular}

because of gangrene due to peripheral vascular disease and neuropathy.

Pedal pulses were easily palpable in most patients, and in none were symptoms of intermittent claudication elicited. Radiographs of the feet have been done in 14, showing arterial calcification in five.

\section{The Cardiovascular System}

Four patients (three middle-aged women and one 73 year old man) have had five myocardial infarcts, three of which were fatal. One patient had atrial fibrillation and one complete heart block. There were no unexplained episodes of congestive heart failure.

Ten patients had hypertension without proteinuria or clinical evidence of diabetic nephropathy. Five patients have had cerebrovascular accidents with hemiplegia, and one a femoral thrombosis.

\section{Other Complications}

Nine $(8.6 \%)$ have had pulmonary tuberculosis, in two of whom cor pulmonale was the cause of death. Two patients have chronic liver disease (one alcoholic) and two others are alcoholic.

\section{Prognosis}

After 15-30 years of diabetes mellitus, when last seen 64 $(61 \%)$ of these 105 Ethiopian diabetic patients were leading independent lives in reasonably good general health, although several have visual problems. Four are chronically ill with renal failure, and six are totally dependent because of amputation (1), hemiplegia (2) and blindness (3). Thirty-one (29.5\%) have died during the 7 -year period. The causes of death are given in Table 1.

\section{Discussion}

Since the discovery of insulin, many diabetic patients in Europe and North America have lived for 40 or 50 years with the disease, and their prognosis is now largely de- termined by the characteristic long-term complications. Simple survival is a major challenge in Ethiopia and other African countries where poverty is common, insulin supplies erratic and medical care sparse, particularly for the insulin-dependent patient. At one time it was thought that the vascular and neurological complications were uncommon in African diabetic subjects, but when duration is considered and follow-up improved it is clear (Table 2) that diabetic subjects on this continent are as prone to these problems as those elsewhere [4-9].

Retinopathy has been reported in $38 \%$ of the general diabetic population of all durations in the USA [10] and Britain [10] and in 45\% of American juvenile diabetic patients after 20 years of disease [10]. Proteinuria was present in $38 \%$ of American juvenile diabetic subjects after 25 years of disease. Similarly, the specific microvascular complications of diabetes (retinopathy and nephropathy) were seen in $38 \%$ and $30 \%$, respectively, of these Ethiopians who had been diabetic for 15-30 years, and neuropathy was found in 52\%.

Thus, 'diabetic triopathy' is as common in Ethiopian diabetic patients after 15-30 years of disease as one would expect from a large Belgian study which concluded that "diabetic triopathy is a function of duration and intensity of diabetes and more precisely of hyperglycaemia" [11]. Good metabolic control is difficult in Ethiopia and poor control common, because of erratic follow-up, high cost of drugs relative to income, economic difficulties in dietary control, unavailability of drugs in rural hospitals, etc. [12].

On the other hand, diabetic macrovascular disease was not a major clinical problem in this group of Ethiopian patients, although more detailed prospective studies are needed to define the exact prevalence. Only four patients had myocardial infarcts, which are generally uncommon in Ethiopia [13], and only two had symptomatic peripheral vascular disease. It is interesting that in the only published report of myocardial infarction in Ethiopians two of the five patients were diabetic [14].

In the USA, about $67 \%$ of diabetic deaths are due to cardiovascular disease, and $9 \%$ to renal disease [10]. In 
contrast, 11 of 31 deaths (35\%) in this series of Ethiopians were related to nephropathy with renal failure and only eight $(25 \%)$ due to cardiovascular catastrophes, again suggesting that macrovascular disease is a less common clinical problem in this population.

Although retinopathy was common, cataracts were clinically more important as a cause of poor vision and blindness in Ethiopian diabetic patients. Few helpful statistics exist: senile cataracts were the cause of $20 \%$ of unilateral, and $46 \%$ of bilateral, blindness in an Ethiopian eye ward, but the incidence of diabetes was not mentioned [15]. The risk of visually significant cataracts, especially posterior subcapsular opacities, has been shown to increase with duration of diabetes [16]; the $40 \%$ occurrence in this group of patients whose mean age was only 53.7 years is, however, very high.

Acknowledgements. This study was presented in part at the 17th Annual Conference of the Ethiopian Medical Association, in May 1981. Sister Yemegnushal Demissie is thanked for her regular help with the diabetic outpatients, and Wo. Nigiste Limeneh for typing the manuscript.

\section{References}

1. WHO Expert Committee on diabetes mellitus (1980) Second Report. WHO Technical Report Series No.646, WHO Geneva

2. The Ministry of Health, Addis Ababa, Ethiopia (1980) Health manpower study-Ethiopia. United Printers, Addis Ababa

3. Lester FT (1983) Nephropathy in Ethiopian diabetics. Ethiop Med J 21: 85-88

4. Otim MA (1975) Preliminary observations on diabetic retinopathy in Ugandan Africans. East Afr Med J 52: 63-69
5. Abdullah MS (1978) Diabetic nephropathy in Kenya. East Afr Med J 55: 513-518

6. Mhando PA, Yudkin JS (1980) The pattern of diabetic complications in African patients in Dar es Salaam. Trop Geogr Med 32: $317-323$

7. Adetuyibi A (1976) Diabetes in the Nigerian African. I. Review of long term complications. Trop Geogr Med 28: 155-159

8. Sankalé M, Sow AM, Signaté S (1970) Aspects du diabète sucré chez le noir Africain à Sénégal. Afr J Med Sci 1:17-31

9. Lester FT, Abdulkadir J, Larson D, Quanna P (1976) Diabetes mellitus: clinical features in 404 Ethiopians. Ethiop Med J 14: 185-198

10. U.S. Department of Health Education and Welfare (1978) Diabetes Data, Compiled 1977. Department of Health Education and Welfare publication No. (NIH) 78-1468

11. Pirart J (1978) Diabetes mellitus and its degenerative complications: a prospective study of 4400 patients observed between 1947 and 1973. Diabetes Care 1:252-263

12. Lester FT, Demissie Y (1977) An assessment of diabetic control in Ethiopians attending a diabetic clinic. Ethiop Med J 15: 133-140

13. Lester FT, Tsega E (1976) The pattern of adult medical admissions in Addis Ababa, Ethiopia. East Afr Med J 53:620-634

14. Teklu B, Teferra A, Parry EHO (1969) Myocardial infarction in Ethiopians. Ethiop Med J 7: 17-24

15. Rokos L (1968) Blindness in Ethiopia. East Afr Med J 45: 407-409

16. Prchal J, Skalka H, Clements R, Bradley EL, Conrad ME, Pittman C (1980) Diabetes and risk of cataract development. Metab Paed Ophthalmol 4: 185-189

Received: 7 December 1982

and in revised form: 30 March 1983

Dr. F.T. Lester

Box 30432

Addis Ababa

Ethiopia 